\title{
Thermodynamic Properties of Hydrogen + Tetra- $n$-Butyl Ammonium Bromide Semi-Clathrate Hydrate
}

\author{
Shunsuke Hashimoto, Takaaki Tsuda, Kyohei Ogata, Takeshi Sugahara, \\ Yoshiro Inoue, and Kazunari Ohgaki
}

Division of Chemical Engineering, Graduate School of Engineering Science, Osaka University, 1-3 Machikaneyama,
Toyonaka, Osaka 560-8531, Japan

Correspondence should be addressed to Shunsuke Hashimoto, shunsuke@cheng.es.osaka-u.ac.jp

Received 5 April 2009; Accepted 17 September 2009

Academic Editor: Jae Lee

Copyright (๑) 2010 Shunsuke Hashimoto et al. This is an open access article distributed under the Creative Commons Attribution License, which permits unrestricted use, distribution, and reproduction in any medium, provided the original work is properly cited.

Thermodynamic stability and hydrogen occupancy on the hydrogen + tetra- $n$-butyl ammonium bromide semi-clathrate hydrate were investigated by means of Raman spectroscopic and phase equilibrium measurements under the three-phase equilibrium condition. The structure of mixed gas hydrates changes from tetragonal to another structure around $95 \mathrm{MPa}$ and $292 \mathrm{~K}$ depending on surrounding hydrogen fugacity. The occupied amount of hydrogen in the semi-clathrate hydrate increases significantly associated with the structural transition. Tetra- $n$-butyl ammonium bromide semi-clathrate hydrates can absorb hydrogen molecules by a pressure-swing without destroying the hydrogen bonds of hydrate cages at $15 \mathrm{MPa}$ or over.

\section{Introduction}

Recently, gas hydrates and other clathrate materials [1] have become one of attractive media that have a huge potential for effective applications of $\mathrm{H}_{2}$ storage and transportation. The $\mathrm{H}_{2}$-mixed gas hydrates with the assistance of suitable additives enable us to perform the $\mathrm{H}_{2}$ storage under much lower-pressure conditions than the simple $\mathrm{H}_{2}$ hydrate [2]. Tetrahydrofuran (hereafter, THF) and tetra- $n$-butyl ammonium salts are well known as the additives [3-9]. In addition, the reversible technique of storage and/or release of $\mathrm{H}_{2}$ by pressurizing or depressurizing without the destruction of hydrate cages are more suitable for the $\mathrm{H}_{2}$ storage than $\mathrm{H}_{2}$ absorbing alloys. For example, in the case of metal hydride, $\mathrm{H}_{2}$ storage amount of $\mathrm{Mg}_{2} \mathrm{Ni}\left(\mathrm{A}_{2} \mathrm{~B}\right.$ type, relatively light material) is 3.6 mass $\%$. However, the $\mathrm{H}_{2}$ storage and release of these metal hydrides are often accompanied by a relatively large enthalpy-change of $30-60 \mathrm{~kJ} / \mathrm{mol}$. On the other hand, although $\mathrm{H}_{2}$ storage amount of clathrate hydrate is smaller than that of metal hydride, the heating to release $\mathrm{H}_{2}$ is unnecessary for the reversible technique of storage and release of $\mathrm{H}_{2}$ by pressurizing and depressurizing. There are some reports about above storage and release method on the THF hydrate [10-12].

The hydrate formed from tetra- $n$-butyl ammonium salt solution has been known as a semi-clathrate hydrate where the quaternary ammonium cation and anion are incorporated with the water molecules to construct the hydrate cage [13]. It is reported that tetra- $n$-butyl ammonium salts can form various unit-cell structures. For example, tetra- $n$-butyl ammonium bromide (hereafter, TBAB) forms two unit-cell structures (tetragonal and orthorhombic) depending on the concentration of aqueous solution $[14,15]$. In our previous study, the cage occupancy of $\mathrm{H}_{2}$ has been investigated by use of phase equilibrium measurements and Raman spectroscopic analyses for two structures of $\mathrm{H}_{2}+\mathrm{TBAB}$ semiclathrate hydrates up to $15 \mathrm{MPa}$ [8]. Most recently, we have reported that hydrogen-induced structural transition from cubic to another structure (probably tetragonal) occurs on $\mathrm{H}_{2}$ + tetra- $n$-butyl ammonium fluoride (hereafter, TBAF) semi-clathrate hydrate [16]. The storage amount of $\mathrm{H}_{2}$ in $\mathrm{H}_{2}+$ TBAF semi-clathrate hydrate drastically increases with the structural transition. These results imply that hydrogen bonds of semi-clathrate hydrate have flexibility. 
In the present study on $\mathrm{H}_{2}+$ TBAB semi-clathrate hydrates, we have two research objectives: (1) thermodynamic property including hydrate structures and $\mathrm{H}_{2}$ occupancy, and (2) capability of reversible storage and release and storage capacity of $\mathrm{H}_{2}$. Firstly, the cage occupancy of $\mathrm{H}_{2}$ and structural transition for the $\mathrm{H}_{2}+\mathrm{TBAB}$ semi-clathrate hydrate under the three-phase equilibrium conditions were investigated by use of in situ Raman spectroscopy. Secondly, phase equilibrium (pressure-temperature) relations for the ternary mixtures of $\mathrm{H}_{2}+\mathrm{TBAB}+$ water at two TBAB concentrations were measured in the pressure region of 15 $190 \mathrm{MPa}$. Finally, the capability of reversible storage and release of $\mathrm{H}_{2}$ was evaluated by in situ Raman spectroscopic analysis using isothermal pressure-swing.

\section{Experimental Section}

2.1. Materials. Research-grade $\mathrm{H}_{2}$ (six nine purity), having the maximum impurity of $0.2 \mathrm{ppm}$ nitrogen, was obtained from the Neriki Gas Co., Ltd. Research grade TBAB of $98 \mathrm{~mol} \%$ up and the distilled water were obtained from the Wako Pure Chemical Industries, Ltd. All of them were used without further purifications.

2.2. Apparatus. A high-pressure optical cell for both the phase equilibrium and the Raman spectroscopic measurements had a pair of sapphire ( $\mathrm{Ti}$ free) windows on both the upper and lower sides. The high-pressure optical cell was the same as previous one [16] except for the window material. The maximum working pressure of high-pressure optical cell was $400 \mathrm{MPa}$. The temperature-controlled water was circulated constantly in the exterior jacket of the highpressure optical cell. A ruby ball was enclosed into the highpressure optical cell. The contents were agitated by the ruby ball, which was rolled around by the vibration from outside.

The system temperature was measured within an uncertainty of $0.02 \mathrm{~K}$ using a thermistor probe (Takara D-632), which was inserted into a hole in the cell wall. The probe was calibrated with a $\mathrm{Pt}$ resistance thermometer defined by ITS-90. The system pressure was measured by a pressure gage (Valcom VPRT) calibrated by RUSKA quartz Bourdon tube gage (Direct Reading Pressure Gage, series 6000) with an estimated maximum uncertainty of $0.01 \mathrm{MPa}$ (low pressure)-0.1 MPa (high pressure).

\subsection{Procedures}

2.3.1. Thermodynamic Property. The aqueous TBAB solution prepared at a desired concentration $(x=0.037$ which is the stoichiometric concentration of tetragonal TBAB hydrate, or 0.020 which is lower than the stoichiometric concentration of orthorhombic TBAB hydrate [14]) was introduced into the evacuated high-pressure optical cell. The contents were pressurized up to a desired pressure by supplying $\mathrm{H}_{2}$ and then cooled and agitated with an enclosed ruby ball to prepare the gas hydrate. After the formation of gas hydrates, the system temperature was risen gradually (about $0.1 \mathrm{~K} /$ hour) to leave a few seed crystals. In this state, the system temperature was kept constant for more than one day, and the three-phase equilibrium condition was determined. Since then the system temperature was dropped little by little (about $0.05 \mathrm{~K} /$ hour) to prepare the single crystal of gas hydrate under the three-phase (hydrate + aqueous solution + gas) coexisting state. We also paid enough attention to preparing as few single crystals as possible. This single crystal was analyzed through a sapphire window ( $\mathrm{Ti}$ free) by in situ Raman spectroscopy using a laser Raman microprobe spectrophotometer with multichannel CCD detector. The argon ion laser beam (wavelength: $514.5 \mathrm{~nm}$ ) condensed to $2 \mu \mathrm{m}$ in spot diameter from the object lens was irradiated to the sample through the upper sapphire window. The backscatter of the opposite direction was taken in with the same lens. The spectral resolution was $\sim 0.7 \mathrm{~cm}^{-1}$.

2.3.2. Storage Capacity of $\mathrm{H}_{2}$. In the isothermal Raman spectroscopic measurement, an aqueous TBAB solution prepared at $x=0.037$ was introduced into the evacuated high-pressure optical cell. To prepare the TBAB hydrate, the contents were supercooled and agitated with an enclosed ruby ball. After the formation of gas hydrates, the system temperature was kept constant, and the contents were annealed for more than one day at $283.15 \mathrm{~K}$ to complete the hydrate crystallization, which was slightly lower than the equilibrium temperature of TBAB hydrate at atmospheric pressure. Then, the contents were pressurized up to a desired pressure by supplying $\mathrm{H}_{2}$, and the cell was kept static to establish the two-phase $\left(\mathrm{H}_{2}\right.$ gas and hydrate phases) equilibrium state. After one day, the hydrate phase was analyzed under the isothermal condition $(283.15 \mathrm{~K})$ through a sapphire window by in situ Raman spectroscopy.

In addition, the $\mathrm{H}_{2}+\mathrm{TBAB}$ hydrate was prepared from compressed $\mathrm{H}_{2}$ and aqueous solution in advance, and $\mathrm{H}_{2}$ was once released from the $\mathrm{H}_{2}+$ TBAB hydrate at $283.15 \mathrm{~K}$ by depressurization. Then, the TBAB hydrate was pressurized again up to a desired pressure by $\mathrm{H}_{2}$, and after one day or more, the hydrate was analyzed under isothermal two-phase equilibrium condition by in situ Raman spectroscopy. For convenience, the description of "repressurizing method" is adopted hereafter in this paper.

\section{Results and Discussion}

3.1. Thermodynamic Property. The Raman spectra for the $\mathrm{H}_{2}+$ TBAB semi-clathrate hydrate system under the threephase equilibrium condition are shown in Figures $1(x=$ $0.037)$ and $2(x=0.020)$. The characteristic Raman peaks derived from $\mathrm{TBAB}$ molecule are detected around 700$1500 \mathrm{~cm}^{-1}$ and $2800-3000 \mathrm{~cm}^{-1}$ in the hydrate phase. The figures also include the single peak $\left(4132 \mathrm{~cm}^{-1}\right)$ of $\mathrm{H}_{2}$ stretching vibration and the broad peak (around $3100 \mathrm{~cm}^{-1}$ ) corresponding to the $\mathrm{O}-\mathrm{H}$ vibration of host water lattice for the $\mathrm{H}_{2}+$ TBAB semi-clathrate hydrate. The $\mathrm{H}_{2}$ vibration peak is normalized by use of one of TBAB peaks. The position and shape of the peak derived from $\mathrm{H}_{2}$ obtained in the present study agree well with those of previous reports $[6,8]$. The Raman spectra reveal that the $\mathrm{H}_{2}$ selectively occupies the empty S-cages of semi-clathrate hydrate, while the butyl-group of TBAB molecule occupies 


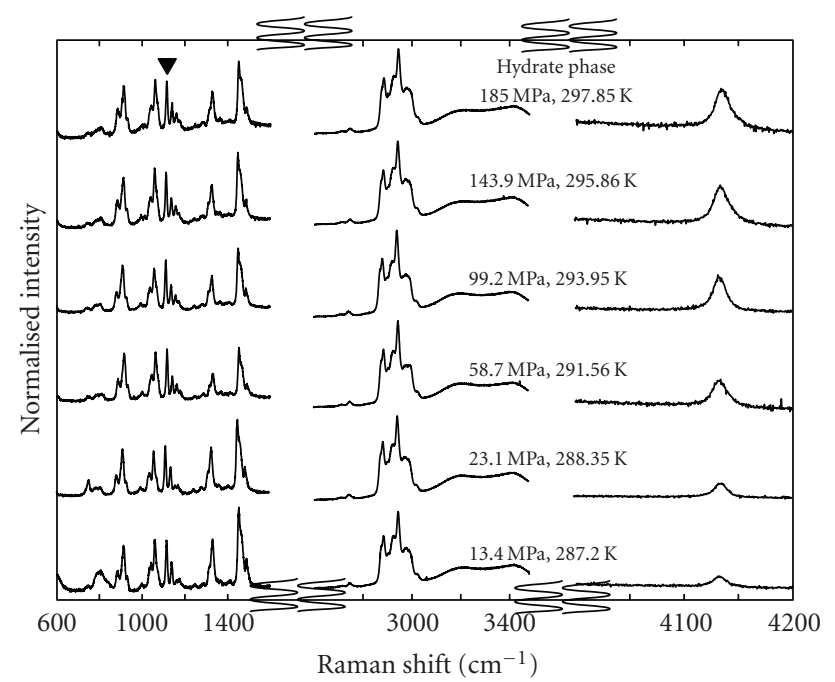

Figure 1: Raman spectra originated in TBAB, $\mathrm{H}_{2}$, and host lattice of water for the $\mathrm{H}_{2}+\mathrm{TBAB}$ semi-clathrate hydrate at $x=0.037$. Closed inverted-triangle represents the peak used for the normalization of $\mathrm{H}_{2}$ vibration peak.

the other cages completely under the present experimental conditions.

Normalized peak of $\mathrm{H}_{2}$ vibration becomes larger and larger with the pressure increasing, which means the increase of entrapped $\mathrm{H}_{2}$ molecules. As shown in Figure 1, in the case of $x=0.037$, Raman peak ratio of $\mathrm{H}_{2}$ to TBAB increases gradually as pressure increasing until ca. $100 \mathrm{MPa}$, while the increment of $\mathrm{H}_{2}$ peak with pressure increasing seems to become small in the higher-pressure region. On the other hand, in the case of $x=0.020$, Raman peak ratio of $\mathrm{H}_{2}$ changes discontinuously around $100 \mathrm{MPa}$ as shown in Figure 2 (shaded region). The normalized peak area of $\mathrm{H}_{2}$ in the case of $x=0.020$ increases dramatically compared with that of $x=0.037$ at similar pressure more than $99 \mathrm{MPa}$. In addition, the Raman peaks of TBAB and water change significantly on reaching $c a$. $100 \mathrm{MPa}$ in $x=0.020$, which differs in results from the case of $x=0.037$. The peaks of $\mathrm{TBAB}$ at high pressures in $x=0.020$ are closely similar to those of the other structure (probably orthorhombic) obtained in our previous study [8]. The orthorhombic structure $\left(\mathrm{TBAB} \bullet 38 \mathrm{H}_{2} \mathrm{O}\right)$ [15] has more empty S-cages and can entrap much more $\mathrm{H}_{2}$ than the tetragonal one $\left(\mathrm{TBAB} \bullet 26 \mathrm{H}_{2} \mathrm{O}\right)$.

The phase equilibrium (pressure-temperature) relations for the $\mathrm{H}_{2}+$ TBAB semi-clathrate hydrate systems are summarized in Table 1 and shown in Figure 3. The threephase equilibrium curves obtained in the present study join smoothly with those of our previous data $[6,8]$. The characteristic slope change $(\mathrm{d} p / \mathrm{d} T)$ derived from the structural transition on the three-phase equilibrium curve exists at $\sim 95 \mathrm{MPa}$ and $292 \mathrm{~K}$ only in the case of $x=0.020$. The phase behavior and structural transition of $\mathrm{H}_{2}+\mathrm{TBAB}$ semi-clathrate hydrate system are closely similar to those of $\mathrm{H}_{2}+$ TBAF semi-clathrate hydrate system [16], except that the transition condition of $\mathrm{H}_{2}+\mathrm{TBAB}$ semi-clathrate

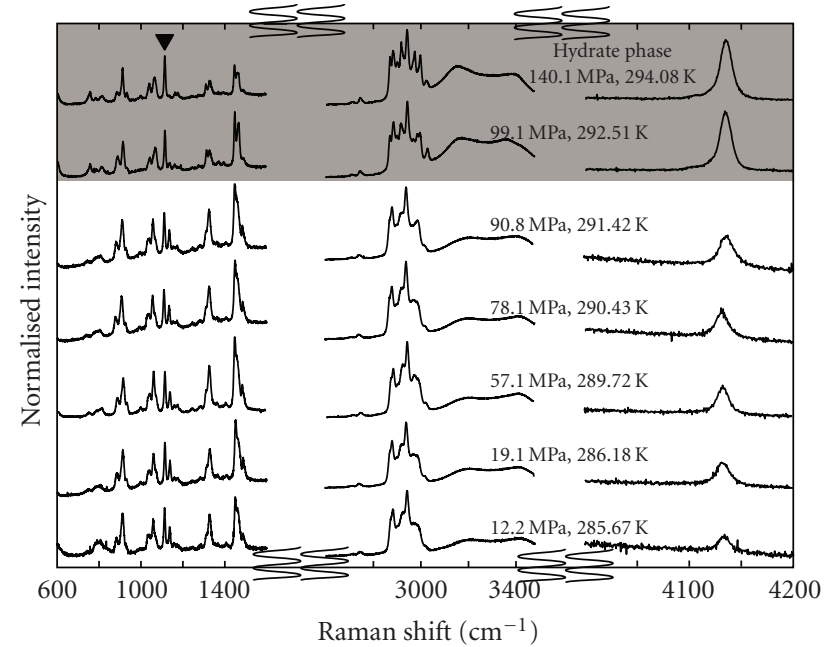

FIgure 2: Raman spectra originated in TBAB, $\mathrm{H}_{2}$, and host lattice of water for the $\mathrm{H}_{2}+$ TBAB semi-clathrate hydrate at $x=$ 0.020. Closed inverted-triangle represents the peak used for the normalization of $\mathrm{H}_{2}$ vibration peak.

hydrate is much severer (the transition pressure is $\sim 90 \mathrm{MPa}$ higher) than that of $\mathrm{H}_{2}+$ TBAF semi-clathrate hydrate [16].

3.2. Storage Capacity of $\mathrm{H}_{2}$. Raman spectroscopy exhibits that $\mathrm{H}_{2}$ can be absorbed in TBAB hydrates without destroying the hydrogen bonds of hydrate cages at $15 \mathrm{MPa}$ or over by use of isothermal pressure-swing. The results from "repressurizing method" (please refer to the experimental section for details) are shown in Figure 4 accompanied with those of Raman spectroscopic measurement under the stability boundary conditions. The $y$-axis represents the peak area of $\mathrm{H}_{2}$ normalized by one of peaks corresponding to TBAB molecule. As shown in Figure 4, normalized Raman peak area of $\mathrm{H}_{2}$ resulted from isothermal pressure-swing increases gradually as pressure rises and is coincident with the $\mathrm{H}_{2}$ peak area measured under the stability boundary conditions. In the case of $\mathrm{H}_{2}$ absorption to fresh TBAB hydrate, Raman peak area of $\mathrm{H}_{2}$ reaches only about $70 \%$ of the value obtained from "repressurizing method" at the same pressure. These results disagree with those of s-II THF hydrate system [11]. The discrepancy in hydrate structures results in that $\mathrm{H}_{2}$ cannot diffuse freely in fresh TBAB hydrate because the empty S-cages do not connect successively. In the case of "repressurizing method," the release of $\mathrm{H}_{2}$ from $\mathrm{H}_{2}+\mathrm{TBAB}$ hydrate induces the secondary structural change of TBAB hydrate; for example, the position of nitrogen or bromine atom connected with host water may be changed. In fact, the crystal appearance of TBAB hydrate changes from clear to cloudy at the moment $\mathrm{H}_{2}$ released from $\mathrm{H}_{2}+\mathrm{TBAB}$ hydrate. The secondary TBAB hydrate prepared by $\mathrm{H}_{2}$ release from $\mathrm{H}_{2}+\mathrm{TBAB}$ hydrate may enable us to perform the reversible $\mathrm{H}_{2}$ storage and release. Figure 4 also shows that the normalized peak area of $\mathrm{H}_{2}$ is not saturated even if the pressure reaches about $200 \mathrm{MPa}$; that is, the empty S-cages cannot be occupied completely by $\mathrm{H}_{2}$ at least $200 \mathrm{MPa}$. 
TABLE 1: Three-phase equilibrium conditions of $\mathrm{H}_{2}+\mathrm{TBAB}$ semi-clathrate hydrate at the TBAB mole fraction of 0.020 and 0.037 in highpressure region. The conditions in low-pressure region are shown in our previous papers $[6,8] . x$ represents the mole fraction of TBAB aqueous solution.

\begin{tabular}{|c|c|c|c|c|c|}
\hline & $T(\mathrm{~K})$ & $p(\mathrm{MPa})$ & & $T(\mathrm{~K})$ & $p(\mathrm{MPa})$ \\
\hline \multirow{3}{*}{$x=0.020$} & 286.45 & 19.5 & $x=0.037$ & 288.35 & 23.1 \\
\hline & 288.23 & 35.6 & tetragonal & 291.56 & 58.7 \\
\hline & 290.07 & 58.0 & & 293.95 & 99.2 \\
\hline$\uparrow$ & 290.97 & 78.8 & & 295.86 & 143.9 \\
\hline tetragonal & 291.53 & 91.6 & & 297.85 & 185.0 \\
\hline new structure & 292.87 & 101.3 & & & \\
\hline$\downarrow$ & 294.75 & 140.6 & & & \\
\hline
\end{tabular}

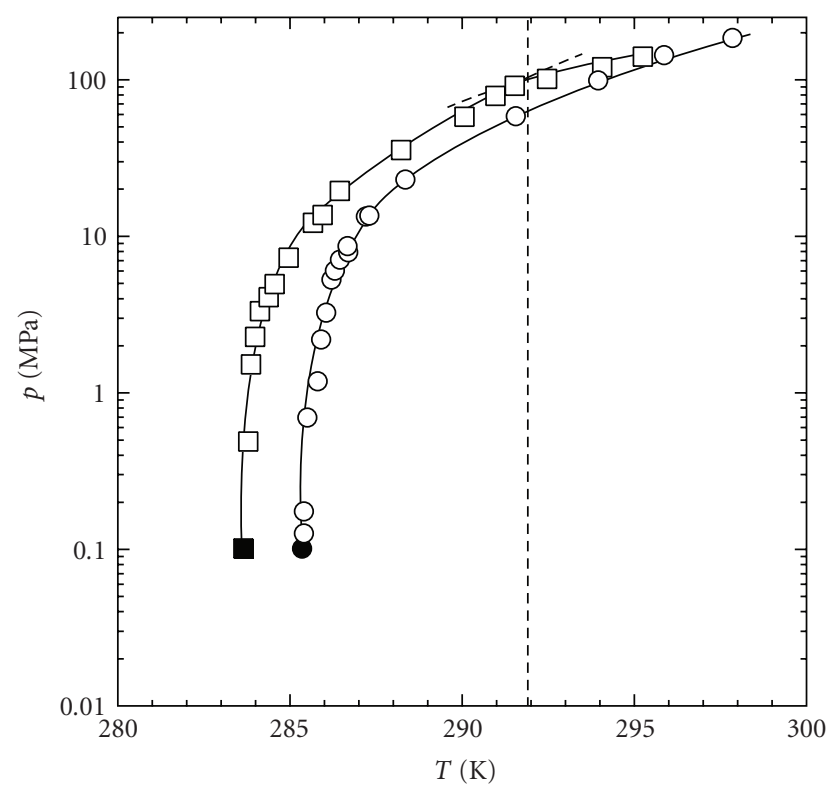

TBAB hydrate $(x=0.020)$

- TBAB hydrate $(x=0.037)$

$\square \mathrm{H}_{2}+$ TBAB hydrate $(x=0.020)$

$\mathrm{O} \mathrm{H}_{2}+$ TBAB hydrate $(x=0.037)$

FIgURE 3: Three-phase equilibrium curves of the $\mathrm{H}_{2}+$ TBAB semi-clathrate hydrates; closed keys represent the three-phase equilibrium points of simple TBAB semi-clathrate hydrates under the atmospheric conditions. The solid lines are fitting lines for experimental data.

\section{Conclusion}

The thermodynamic stability and $\mathrm{H}_{2}$ occupancy for the $\mathrm{H}_{2}$ + TBAB semi-clathrate hydrate system were investigated by phase equilibrium (pressure-temperature) relation and Raman spectra measured at two mole fractions $(x=0.020$ or $0.037)$ of TBAB aqueous solution. In the case of $x=0.020$, the structural transition from tetragonal to another structure is occurred around $95 \mathrm{MPa}$ and $292 \mathrm{~K}$. The structure after the structural transition can store much more $\mathrm{H}_{2}$ molecules than the tetragonal one. Raman spectroscopic analysis with isothermal pressure-swing absorption reveals that $\mathrm{H}_{2}$ can be absorbed in the TBAB hydrates without destroying the

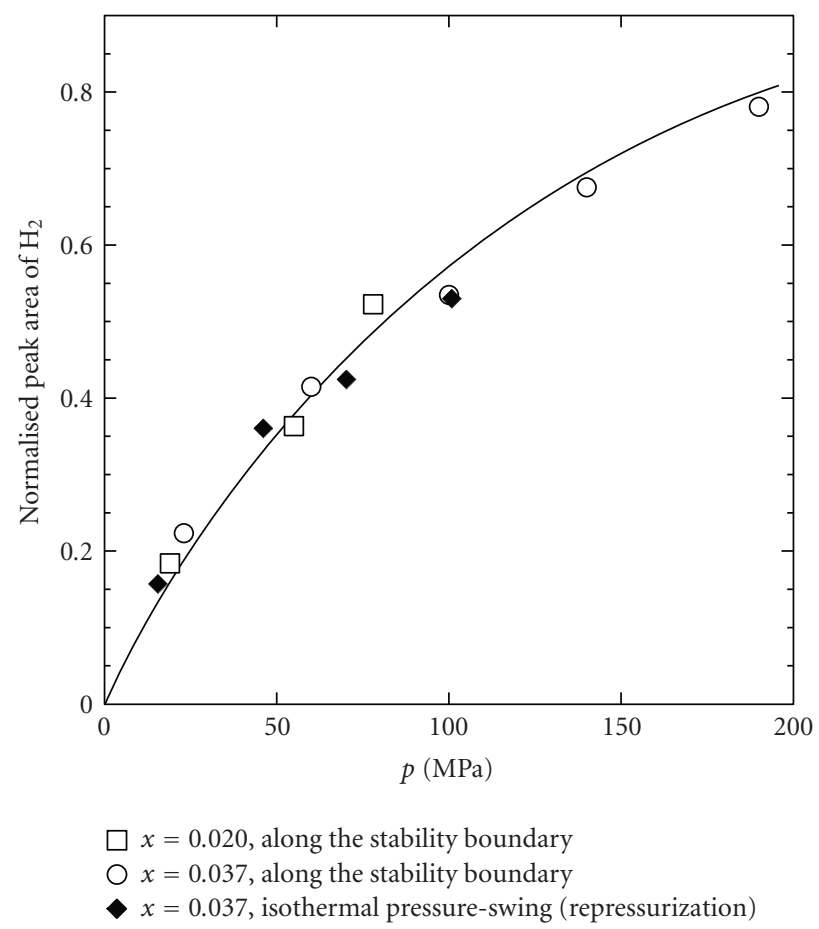

Figure 4: Pressure dependence of normalized Raman peak area corresponding to $\mathrm{H}_{2}$ for the $\mathrm{H}_{2}+\mathrm{TBAB}$ semi-clathrate hydrate system.

hydrogen bonds of hydrate cages. The storage amount of $\mathrm{H}_{2}$ for the repressurization to the used TBAB hydrate after $\mathrm{H}_{2}$ release increases compared with that of fresh TBAB hydrate. It remains possible to perform the reversible storage and release of $\mathrm{H}_{2}$ in $\mathrm{TBAB}$ hydrate without destroying hydrate cages.

\section{Notations}

p: Pressure, $\mathrm{Pa}$

$T$ : Temperature, $\mathrm{K}$

$x$ : Mole fraction of TBAB in the aqueous solution.

\section{Acknowledgments}

This work was financially supported by Grant-in-Aid for Scientific Research to TS (Young Research, B, 19760491) and 
partially supported by a research Grant from The Mazda Foundation and Grant-in-Aid for Scientific Research to SH (Young Start-Up, 20810016). T. Tsuda shows his gratitude for the center of excellence (COE) program of Osaka University. The authors gratefully acknowledge the Division of Chemical Engineering, Graduate School of Engineering Science, Osaka University for the scientific support by "GasHydrate Analyzing System (GHAS).”

\section{References}

[1] T. A. Strobel, Y. Kim, G. S. Andrews, et al., "Chemical-clathrate hybrid hydrogen storage: storage in both guest and host," Journal of the American Chemical Society, vol. 130, no. 45, pp. 14975-14977, 2008.

[2] J. S. Zhang and J. W. Lee, "Equilibrium of hydrogen + cyclopentane and carbon dioxide + cyclopentane binary hydrates," Journal of Chemical \& Engineering Data, vol. 54, no. 2, pp. 659-661, 2009.

[3] L. J. Florusse, C. J. Peters, J. Schoonman, et al., "Stable low-pressure hydrogen clusters stored in a binary clathrate hydrate," Science, vol. 306, no. 5695, pp. 469-471, 2004.

[4] H. Lee, J.-W. Lee, D. Y. Kim, et al., "Tuning clathrate hydrates for hydrogen storage," Nature, vol. 434, no. 7034, pp. 743-746, 2005.

[5] T. A. Strobel, C. A. Koh, and E. D. Sloan, "Hydrogen storage properties of clathrate hydrate materials," Fluid Phase Equilibria, vol. 261, no. 1-2, pp. 382-389, 2007.

[6] S. Hashimoto, S. Murayama, T. Sugahara, H. Sato, and K. Ohgaki, "Thermodynamic and Raman spectroscopic studies on $\mathrm{H}_{2}+$ tetrahydrofuran + water and $\mathrm{H}_{2}+$ tetra- $n$ butyl ammonium bromide + water mixtures containing gas hydrates," Chemical Engineering Science, vol. 61, no. 24, pp. 7884-7888, 2006.

[7] S. Hashimoto, T. Sugahara, H. Sato, and K. Ohgaki, "Thermodynamic stability of $\mathrm{H}_{2}+$ tetrahydrofuran mixed gas hydrate in nonstoichiometric aqueous solutions," Journal of Chemical \& Engineering Data, vol. 52, no. 2, pp. 517-520, 2007.

[8] S. Hashimoto, T. Sugahara, M. Moritoki, H. Sato, and K. Ohgaki, "Thermodynamic stability of hydrogen + tetra- $n$ butyl ammonium bromide mixed gas hydrate in nonstoichiometric aqueous solutions," Chemical Engineering Science, vol. 63, no. 4, pp. 1092-1097, 2008.

[9] A. Chapoy, R. Anderson, and B. Tohidi, "Low-pressure molecular hydrogen storage in semi-clathrate hydrates of quaternary ammonium compounds," Journal of the American Chemical Society, vol. 129, no. 4, pp. 746-747, 2007.

[10] T. A. Strobel, C. J. Taylor, K. C. Hester, et al., "Molecular hydrogen storage in binary THF- $\mathrm{H}_{2}$ clathrate hydrates," Journal of Physical Chemistry B, vol. 110, no. 34, pp. 1712117125, 2006.

[11] K. Ogata, S. Hashimoto, T. Sugahara, M. Moritoki, H. Sato, and K. Ohgaki, "Storage capacity of hydrogen in tetrahydrofuran hydrate," Chemical Engineering Science, vol. 63, no. 23, pp. 5714-5718, 2008.

[12] Y. Nagai, H. Yoshioka, M. Ota, et al., "Binary hydrogentetrahydrofuran clathrate hydrate formation kinetics and models," AIChE Journal, vol. 54, no. 11, pp. 3007-3016, 2008.

[13] L. S. Aladko, Yu. A. Dyadin, T. V. Rodionova, and I. S. Terekhova, "Clathrate hydrates of tetrabutylammonium and tetraisoamylammonium halides," Journal of Structural Chemistry, vol. 43, no. 6, pp. 990-994, 2002.
[14] W. Shimada, T. Ebinuma, H. Oyama, et al., "Separation of gas molecule using tetra- $n$-butyl ammonium bromide semiclathrate hydrate crystals," Japanese Journal of Applied Physics, vol. 42, pp. L129-L131, 2003.

[15] W. Shimada, M. Shiro, H. Kondo, et al., "Tetra- $n$-butylammonium bromide-water (1/38)," Acta Crystallographica Section C, vol. 61, part 2, pp. o65-o66, 2005.

[16] J. Sakamoto, S. Hashimoto, T. Tsuda, T. Sugahara, Y. Inoue, and K. Ohgaki, "Thermodynamic and Raman spectroscopic studies on hydrogen + tetra- $n$-butyl ammonium fluoride semi-clathrate hydrates," Chemical Engineering Science, vol. 63, no. 24, pp. 5789-5794, 2008. 

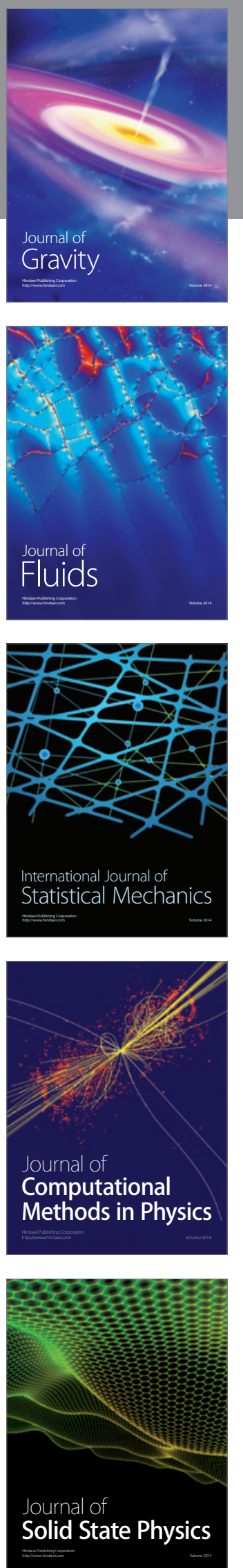

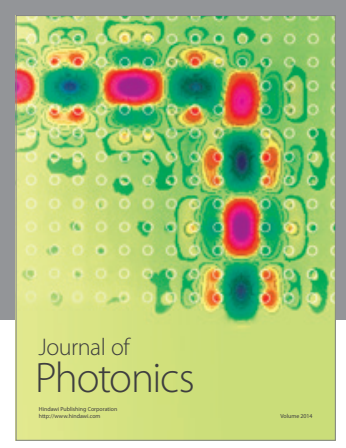

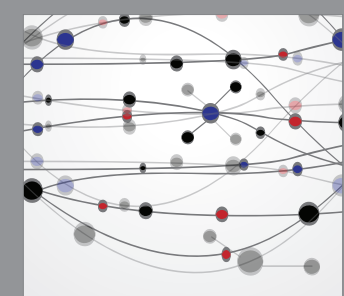

The Scientific World Journal
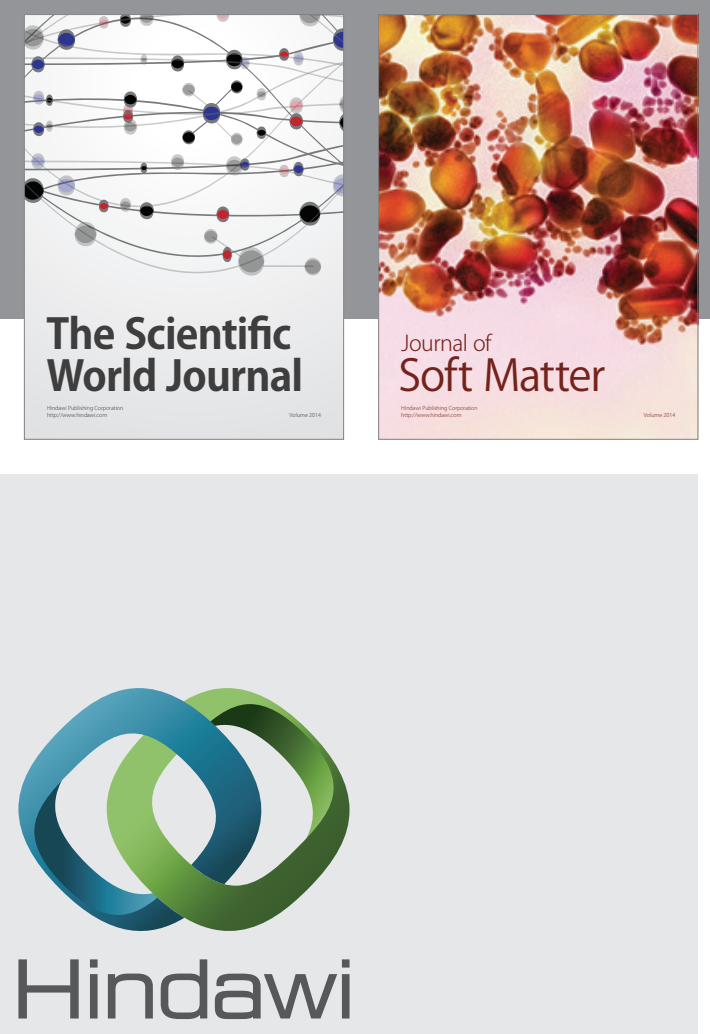

Submit your manuscripts at

http://www.hindawi.com
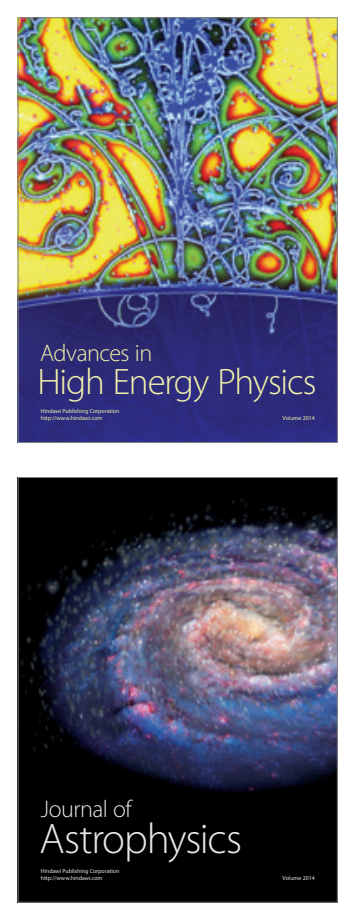
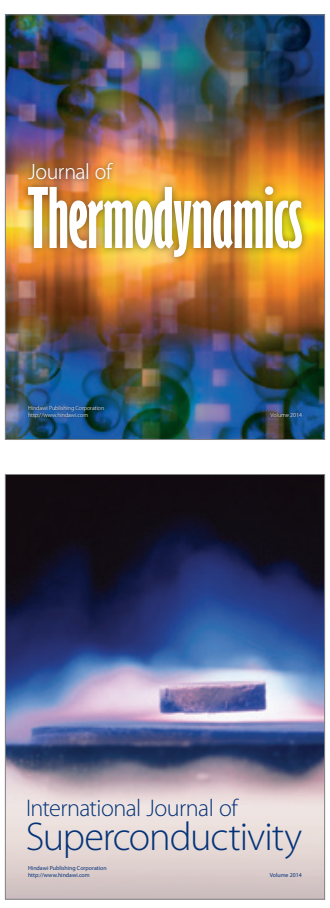
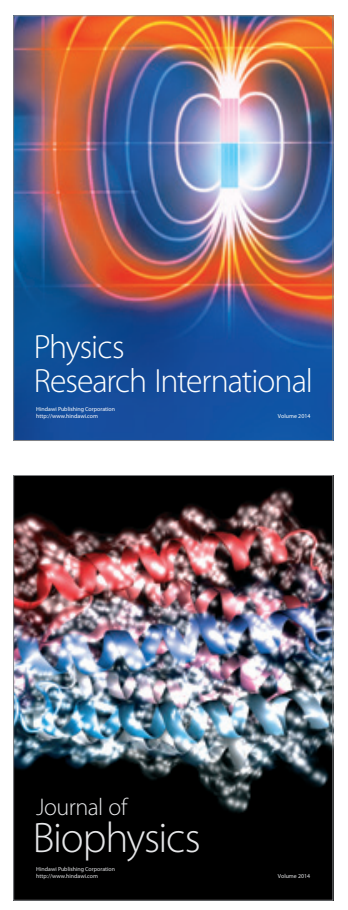
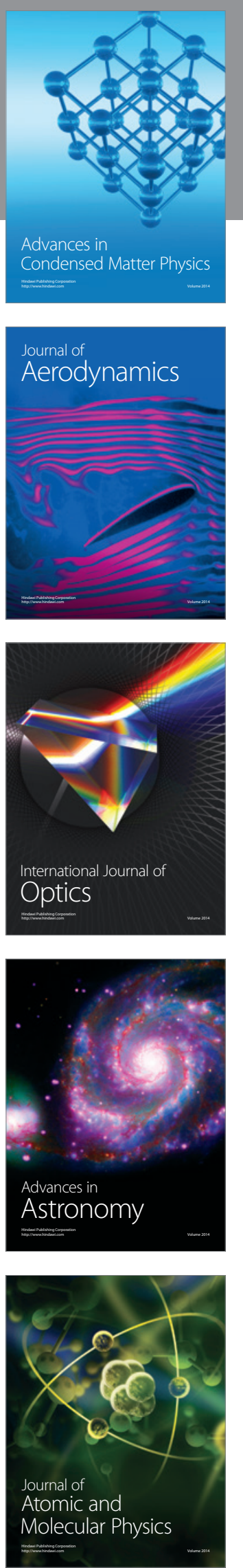